GRIPS Discussion Paper 15-24

\title{
Experiments on Lotteries for Shrouded and Bundled Goods: Investigating The Economics of Fukubukuro.
}

\author{
Chaikal Nuryakin \\ Alistair Munro
}

February 2016

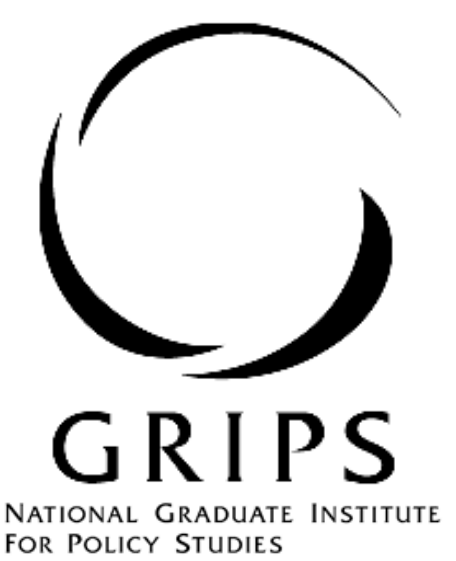

National Graduate Institute for Policy Studies

7-22-1 Roppongi, Minato-ku,

Tokyo, Japan 106-8677 


\title{
Experiments on Lotteries for Shrouded and Bundled Goods: Investigating The Economics of Fukubukuro. ${ }^{1}$
}

\author{
Chaikal Nuryakin
}

Faculty of Economics, Universitas Indonesia

\begin{abstract}
Alistair Munro
National Graduate Institute for Policy Studies (GRIPS), Roppongi 7-22-1, Tokyo, Japan, 106-8677
\end{abstract}

\begin{abstract}
Fukubukuro (or lucky bag) is a familiar institution in Japan and many other countries used by retailers for disposing of unwanted stock during the New Year sales. Two features of the institution are important: First, in fukubukuro, stores bundle goods of related items into sealed bags rather than selling items separately. Secondly, while general information about the contents is provided, details of brands and specifications are concealed creating a lottery for the purchaser. Motivated by the fukubukuro example and the lack of evidence on risk attitudes in lotteries involving goods, we conduct a laboratory experiment and follow-up survey to investigate preferences for lotteries in which the outcomes are bundled or unbundled goods.

In general, we find that risk has a negative effect on subjects' WTP for a product lottery. Nevertheless, a minority of subjects are risk-seeking and value the lottery more highly than the highest valued individual product. Conversely, we do not find much evidence of an uncertainty effect. Although subjects' WTP responses to bundled product lotteries are less heterogeneous than their responses to single product lotteries, there is no significant advantage of selling bundled product lotteries over single product lotteries in relation to subjects' risk preferences. We follow up the experiment with a hypothetical choice

\footnotetext{
${ }^{1}$ We would like to convey gratitude to National Graduate Institute for Policy Studies (GRIPS), Tokyo and Department of Economics, University of Indonesia, Depok for partially funding this research and to AlinHalimatussadiah and JazmanIhsanudin for their superb assistance during experiments.
} 
questionnaire in which we confront subjects with three options for a variety of goods: a certain product, its substitute, and a product lottery. We find that subjects who are riskseeking or have less product knowledge and familiarity are more likely to choose a product lottery. Furthermore, subjects are more likely to choose a product lottery when the choice task consists of complex products rather than simple products. We speculate that risk seeking and less-informed subjects may find a lottery between products to be a direct and simple way to solve their buying decision tasks.

Keywords: fukubukuro, WTP, risk preference, skewness, laboratory experiment. JEL Classification: C91, D81. 


\section{INTRODUCTION.}

Fukubukuro, (literally, lucky bag), is a familiar retail institution in Japan and many other countries in east and south-east Asia, used for disposing of unwanted stock during New Year sales. Many retailers, ranging from small shops to big department stores get involved. In fukubukuro, retailers offer bags or boxes consisting of bundled products at substantially discounted prices. Yet, the main difference that distinguishes fukubukuro from other New Year sales is that retailers sell products in a closed box or bag. That is, the nature of the good is shrouded, creating some risk for the consumer about the nature of the contents. A preference for risk amongst consumers might therefore explain the prevalence of fukuburo but most of the experimental evidence (e.g. Starmer, 2000, Harrison et al, 2007) on risky choice actually suggests that the majority of consumers are risk averse. At first sight therefore bundling goods and turning them into lotteries does not seem to be profit-maximizing. ${ }^{2}$ However, most of the evidence on risk aversion comes from lotteries involving money. It is possible therefore that lotteries involving goods might provoke different behavior.

Motivated by this, we conduct two experiments that mimic some of the features of the fukubukuro experience and test experimentally preferences over lotteries involving goods as outcomes in both a bundled and unbundled setting. One experiment involves real goods in an incentivized setting, but because using real goods restricts the objects of choice somewhat we also conduct a second, hypothetical choice experiment. Our main results are that we find that risk has a negative effect on mean subjects' willingness to pay (WTP) for a product lottery: subjects typically value the lottery less than the weighted average of the valuations of the items sold without risk. At the same time, we find that a proportion of subjects are riskseeking and optimistic, especially towards negatively skewed product lotteries. In addition we find no significant advantage of selling bundled product lotteries over single product lotteries in relation to subjects' risk preferences.

The plan of the paper is as follows. In the next section we provide some institutional background about fukubukuro which may be useful to readers based in countries where the

${ }^{2}$ We readily acknowledge that there may also be strategic motives for the use of fukubukuro. For instance, a retailer with imperfect knowledge of consumer valuations may prefer a lottery over a sale with separate prices for two substitute products. Similarly bundling may be optimal for a firm with some monopoly power (Palfrey, 1983). In this paper we focus on isolating the potential for a psychological motive based on risk attitudes. 
practice is not (yet) common. We discuss the state of the relevant literature on risk with goods as outcomes. Section 3 sets out the research design for the first experiment and results are in section 4. The second experiment is presented in section 5 and then section 6 provides a general discussion.

\section{BACKGROUND.}

Yodobashi Camera — one of the largest electronic chains in Japan—is responsible for one of the highest profile fukubukoro sales (see Figure 1) and provides a natural example. Yodobashi Camera sells various fukubukuro ranging from stationery products to notebook computers. In their fukubukuro, the brand of the product to be received by buyers is shrouded by a special box with a printed product category and prototype picture. For example, Yodobashi Camera sold a digital compact camera fukubukuro, consisting of either a Nikon or a Sony digital compact camera, during the New Year of 2013 for 5,000 yen (see Figure 1). The important characteristic of Yodobashi Camera's fukubukuro is that it randomizes products that have relatively equal values. Secondly, the probability of receiving one product to that of others is also perceived to be equal. Thirdly, it bundles the 'main' product with a series of lower valued, complementary products

\section{INSERT FIGURE 1HERE}

For the purposes of randomizing and, at times, concealing the jackpot prize, a brand retailer does not typically provide much fukubukuro-related information to consumers. Most of the time, the brand retailers use their products' packaging in bag form as the fukubukuro boxes. Even the Apple stores used their MacBook accessory bags as their fukubukuro boxes during the New Year of 2013. Smaller shops and some department stores, on the other hand, prefer to use a plainly colored box, usually in red, with the words "lucky bag" or the word "fukubukuro" written on it, along with their store names. Nevertheless, the retailer deliberately reduces the randomness of fukubukuro by classifying its bundles into narrower categories, such as cameras, notebook computers, and kitchen appliances. It further classifies camera fukubukuro into more specific categories that range from digital compact cameras to digital cameras with an interchangeable mirror lens. Furthermore, every year, the retailer uses a special box for fukubukuro that is complemented with a printed picture of a prototype product that might provide hints of the kind of product that is inside the box (see Figure 1). By this means and by the fact that the firm is long-established and holds such events 
regularly, the retailer deals with the fact that even a loyal customer would need some assurance in buying fukubukuro. ${ }^{3}$

The electronics store model is one type of fukubukuro in which the major uncertainty involved is the brand of a product. An alternative model used by some stores, (e.g., Apple stores) is the use of vertically differentiated products. For instance, Apple's fukubukuro may consist of a MacBook, an Ipad, or an Ipod, each with its own specific accessories (see Figure 2).

\section{INSERT FIGURE 2 HERE}

In other cases, fukubukuro seems to have a general bundling feature across retailers: the bundle consists of a main product and its tie-in (accessories), which are complementary in most cases. For brand retailers especially, fukubukuro may consist of more than one main product (e.g., apparel) and more than one accessory product (e.g., hat). In addition, there are many cases in which the accessories are inferior or have relatively low value compared to the main product.

Fukubukuro is by no means unique: outside of the New Year sales market we see other situations in which subjects are asked to buy a deliberately shrouded product, both in Japan and in other countries. For instance, in the U.S. and Europe some travel booking websites (e.g. expedia.com or lastminute.com) offer 'mystery hotels' in which broad information about location and star rating is given but the actual identity of the hotel is not revealed until after booking. ${ }^{4}$

As we mentioned in the introduction the motives for using fukubukuro seem obscure (and no enlightenment is offered by the retailers themselves). One possibility is that the presence of a significant minority of risk-seeking individuals may be sufficient for sellers to gain more profits from offering goods for sale through lottery. Against this view, the literature on risky choice has provided overwhelming evidence that most individuals are risk-

3 There are additional ways for consumers to know what to expect when buying fukubukuro. For example, on the internet, many people share their experiences by posting photos of the products that they receive. Social media such as Twitter and Facebook have enhanced the quantity and the quality of such information.

${ }^{4}$ Again there may be various motives for this kind of business behaviour including the desire to offer price cuts without provoking retaliation, but the question for us is how consumer's respond to such uncertainty. 
averse in monetary gambles (e.g., Gneezy et al., 2006; Harrison et al., 2007), though the fact that most individuals are generally risk-averse does not rule out the presence of a significant minority of risk-seeking individuals (Deck and Schlesinger, 2012).

Most of the experimental studies over lotteries involve money as the reward, or goods such as store vouchers which are close substitutes for cash. A few studies have evaluated individual risk preferences in the context of goods or non-monetary prizes (e.g. Bohm et al, 1993, Riddell, 2012, Dohmen et al, 2011, Benzion et al, 2012 and Einav et al, 2012). In general researchers find some positive correlation between risk attitudes in the monetary domain and attitudes in other domains, but the correlation is often not strong (Weber et al, 2002). One difficulty in interpreting the significance of such results is that typically the elicitation of risk attitudes in non-monetary domains is not incentivized and in some cases, the questions about non-monetary risk attitudes are much less precise than those involving monetary lotteries. Bohm et al, 1993 run incentivized lotteries involving used cars. Their focus is not on making general conclusions about risk attitudes but they conclude that subject are less prone to preference reversals when a non-monetary good is used. Meanwhile Benzion et al, 2012 (see also the related Tal et al, 2010) have lotteries involving USB sticks and conclude that subjects are broadly risk neutral.

Even if individuals are generally risk averse, there may be specific pleasures to be had from taking part in a lottery over goods. As a New Year's tradition, fukubukuro is regarded as a festival activity, in which the pre-buying rituals are just as important as the purchase itself. For some individuals, fukubukuro may offer the pleasure of suspense from the moment of queuing for the purchase to the moment of unveiling the contents of the box (Caplin and Leahy, 2001). Moreover, as Conlisk, 1993, shows in his utility of gambling model, for the risk-averse consumer, even a tiny utility derived from the suspense of buying a lottery may alter her decision to choose a more risky option.

Leaving aside attitudes to risk, individuals may conceivably overweight the probability of receiving a more preferable product and underweight the probability of receiving a less preferable product (Hey, 1984; Tversky and Kahneman, 1992). In the extreme, they may value fukubukuro as much as they value the best product outcome obtained for certain (Goldsmith and Amir, 2010). Such behavior would be the opposite of what Gneezy et al, 2006 term the 'uncertainty effect' meaning the valuation of a lottery 
below the minimum value of the valuations of its components. ${ }^{5}$

In risky experiments in the laboratory, subjects are typically informed of probabilities but in the case of real-world fukubukuro, sellers do not provide exact probability distributions of outcomes to the consumers as decision makers. ${ }^{6}$ It is also conceivably possible that some subjects are ambiguity lovers when the lottery involves goods.

Given this paucity of evidence, it seems an important first step towards understanding the demand for product lotteries in consumer markets is to investigate risk attitudes for lotteries involving goods. We therefore design an experiment that provides a stripped down and tightly controlled version of fukubukuro. We limit the number of goods and give subjects full information about probabilities and so on. We also eliminate in our design some other possible confounds that may affect subjects' WTP for fukubukuro in a real market, such as limited availability of time and quantity, as well as selling frenzies and other social effects. ${ }^{7}$

\section{VALUATION EXPERIMENT}

\section{Design}

To mimic a minimal version of the fukubukuro system we use two brands of one type of product (A1 and A2) and one brand of a second type of product (B). Details of the actual products are given subsequently. From these three goods we constructed 15 lotteries (see Table 1): seven lotteries involving some chance of receiving either A1 or A2; seven lotteries involving some chance of receiving the bundle A1 and B (denoted as A1B) and some chance of receiving the bundle $\mathrm{A} 2$ and $\mathrm{B}$ (denoted as $\mathrm{A} 2 \mathrm{~B}$ ) and one degenerate lottery for the $\mathrm{B}$ good. The seven lotteries involved different chances of receiving each outcome. Specifically if $p=$ the probability of receiving outcome 1 , then $\mathrm{p}$ was from the following set:

${ }^{5}$ Studies that have tried to replicate Gneezy et al. 2006) with mixed results include, for example, Simonshon 2008), Newman and Mochon 2012), Keren and Williamson 2008), and Rydval et al. 2009).

${ }^{6}$ One possible reason why consumers are willing to trust retailers even without precise information on probabilities is possibly that these firms are well-established and prominent: their reputation would be highly damaged if ex-post it was found that a significant proportion of consumers felt cheated.

${ }^{7}$ Dittmar and Drury 2000) focus on the psychology of particular consumers who might also be the target for sales. 
$\{0,0.125,0.25,0.50,0.75,0.875,1\} .8$ The extreme cases $p \in\{0,1\}$ therefore represent degenerate lotteries when the purchaser knows the bundle with certainty.

\section{INSERT TABLE 1 HERE}

In this situation, for example, a subject's WTP at initial wealth $y$ for a product lottery consisting of a probability of the chance of receiving product A1 $(p)$ and the chance of receiving product $\mathrm{A} 2(1-p)$, is defined implicitly by the equation,

$$
p u(A 1, y-w t p)+(1-p) u(A 2, y-w t p)=u(0, y)
$$

Let $w t p(p, 1-p, x, z)$ be the WTP for a lottery where $\mathrm{x}$ is received with probability $\mathrm{p}$ and $\mathrm{z}$ is received with probability $1-\mathrm{p}$. In this situation a subject is risk-averse (risk loving) when her WTP for a lottery is lower (higher) than the expected WTP of the components of the lottery. That is, for risk aversion:

$$
p * w t p(1,0, x, z)+(1-p) * w t p(0,1, x, z)>w t p(p, 1-p, x, z) .
$$

\section{Implementation.}

In order to minimize ${ }^{9}$ the possible anchoring effects of prior knowledge and market price (Anderson et al., 2007; Harrison et al., 2004), we conducted the experiment in Indonesia using high quality Japanese products that are rarely available in the Indonesian market. After pilot experiments and focus groups, for our experimental goods, we chose a Frixion pen as good A1, Surari pens as good A2, (see the pictures and product information of the goods in the Appendix). Pens are a stationery product that are regularly used and needed by students, but the particular brands are unusual and hard to obtain in Indonesia. For good B we used Kit Kat Green Tea, which again is a brand that is not easily available in Indonesia.

${ }^{8}$ In the presentations of our design, the probabilities of receiving the product are not represented by fractions but by the number of products in what we call the "lottery box." For example, in order to represent the probability of a 0.125 chance of receiving A1 and a 0.875 chance of receiving A2, we presented eight products in the lottery box that consists of one product of A1 and seven products of A2 (an example of the WTP task on the product lottery is available in the Appendix). Therefore, in this paper, it is more convenient for us to represent probabilities as ratios of goods rather than numerically. For example, a 1/7 lottery A1_A2 consists of a 0.125 chance of receiving A1 and a 0.875 chance of receiving A2.

${ }^{9}$ We say "minimize" here because there are always some outside alternatives (substitute goods) for our experimental goods that could be bought by a sufficiently motivated consumer. 
The market price for a typical pen in Japan is approximately 90-180 yen (around one to two euros), while it is approximately 220-300 yen for a typical Kit Kat Green Tea. In Indonesia, a typical pen would cost approximately Rp. 10,000-50,000, while a typical Kit Kat Green Tea would cost approximately Rp. 100,000. We asked the subjects to state their WTP for a given product in the range of Rp. 0-40,000 in the multiples of 1,000 .

To make choices incentive compatible, for each subject one task and one price were randomly chosen for real. In particular, each subject drew one (table tennis) ball from two separate urns, "task urn" and "price urn," to determine the task and the price that would be for real. The task urn consisted of balls numbered 1 to 15 , whereas the price urn consisted of 40 balls numbered 1,000 to 40,000 in 1,000 multiplications. If the chosen task were a (bundled) product lottery, subjects drew the third ball from the "product urn" to determine the product that he or she would receive.

The experiment was conducted using the software z-tree (Fischbacher, 2007), and we employ a within-subject design in which each subject is exposed to the 15 questions in random order. WTP for products and product lotteries by using a two-stage process: first, we gauged the subject's interest in the product; second, we asked them to state their highest value of WTP for the product. ${ }^{10}$

We provided subjects with a practice session consisting of four examples: an individual good (mechanical pencil), bundled goods (mechanical pencil and eraser), a 1/1 product lottery (mechanical pencil or ordinary pencil), and a 1/7 bundled product lottery (mechanical pencil and eraser or ordinary pencil and eraser). Two review questions followed the practice session to test the subjects' understanding of the drawing procedure and the concept of a product lottery. Before the decisions session, we gave subjects the opportunity to use the pens and taste the Kit Kat and supplied them with product information sheets during the session. Furthermore, we asked subjects to complete a short survey on their demographic backgrounds and some follow-up questions on the products used in the experiment after the completion of all their decision tasks. Except for the decision sessions, instructions were provided on each computer monitor and read by an experimenter throughout the experiment

\footnotetext{
${ }^{10}$ We adopted a two-stage decision-making process due to psychological considerations: we expected subjects to think more cautiously about the second question asking for their WTP for a particular product, which is the main question in our design. This method is in general similar to the "cheap talk" used in many valuation studies. In all cases, subjects expressed a positive interest.
} 
(see the screenshots of the instructions in the Appendix).

We conducted two consecutive sessions of a laboratory experiment with 38 students $\left(\mathrm{n}_{1}=21\right.$ and $\left.\mathrm{n}_{2}=17\right)$ at the Department of Economics, (University of Indonesia), on March $10^{\text {th }}$ 2014. ${ }^{11}$ There were 22 males and 16 females; most of them are first- and second-year students (25). All subjects had taken at least one introductory economics course. Each session lasted for 90 minutes. We asked the subjects of the second session to come before the completion of the first session and quarantined them to ensure that no information would be leaked from the first session subjects to the second session subjects. Subjects received Rp. 100,000 (approximately US \$8) as cash reward for their time and participation.

We conducted two review questions after the training session to verify subjects' understanding of the procedure of randomly choosing the decision that would be implemented for real and the concept of a product lottery (see the screenshots of the instructions in the Appendix). Nine subjects answered wrongly to the first review question but none did so to the second review question. We conversed with each of the subjects to give them the correct understanding of the matter. Furthermore, we gave them guidance or explicitly stated that the best strategy for them to respond to the price-drawing procedure is to truthfully reveal their WTP.

\section{RESULTS}

\section{Validity.}

As basic checks of understanding, in addition to the tests of understanding conducted during the experiment we conduct tests of the consistency of choices. Specifically we check for monotonicity and stability, defined as follows. The subject has strongly monotonic preference if she prefers a bundled good more than any of the individual goods in the bundle, i.e., if the WTP values for a bundled good are higher than those for any of the individual goods in the bundle. Preferences are weakly monotonic if WTP for the bundled good is no lower than any of the individual goods. Meanwhile, we say the subject has stable preferences

\footnotetext{
${ }^{11}$ In each session there are two parts: valuation and a hypothetical choice experiment which always came after the valuation exercise.
} 
if she prefers $\mathrm{A} 1$ over $\mathrm{A} 2$ and then $\mathrm{A} 1 \mathrm{~B}$ over $\mathrm{A} 2 \mathrm{~B} .^{12}$

We excluded one subject from the analyses due to her zero valuations for all products. Table 2 provides the results of the monotonicity test for bundle A1B, bundle A2B, and their corresponding products. All of the statistical tests used non-parametric matched pairs onesided test (Wilcoxon signed-rank test). In this table the column $\mathrm{N}(+)$ represents the number of subjects who value the bundle higher than the individual product; $\mathrm{N}(0)$ represents the number of subjects who value the bundle and product equally and the omitted category is the number of subjects who value the product more than the bundle. The results indicate that subjects have strongly monotonic preferences for $\mathrm{A} 1 \mathrm{~B}$ over $\mathrm{A} 1, \mathrm{~A} 1 \mathrm{~B}$ over $\mathrm{B}$, and $\mathrm{A} 2 \mathrm{~B}$ over $\mathrm{A} 2$ but weakly monotonic preferences for A1B over B. Meanwhile, tests for preference stability accept the null that preferences between $\mathrm{A} 1-\mathrm{A} 2$ and $\mathrm{A} 1 \mathrm{~B}-\mathrm{A} 2 \mathrm{~B}$ are consistent. Thus at the basic level, subjects give answers in line with standard expectations.

\section{INSERT TABLE 2 HERE}

Table 3 summarizes the distribution of subjects' WTP responses. It shows that the mean of subjects' WTP for individual products A1, A2, and A2B is higher than their median, which implies that the distribution is right-skewed. Meanwhile, the distribution of subjects' WTP for bundled product A1B is left-skewed. Thus, most of the subjects' WTP responses lie on the bottom half of the price levels for $\mathrm{A} 1, \mathrm{~A} 2$, and $\mathrm{AB}$ and the bottom half of the price levels for A1B (See Figure 3 for the distribution of WTP for A1, A2, A1B and A2B). In the table, E(WTP) means expected WTP based on the weighted average of the mean WTP for the degenerate lotteries. It can be seen that for all lotteries involving some chance of winning both products, E(WTP) lies above the mean WTP. In other words, at the aggregate level, subjects are risk averse over all 10 lotteries. For the individuals, the pattern is different, as witnessed by the sign test in the last column of Table 3. This column reports the results of a matched pairs sign test, in which the pairs are WTP and E(WTP) for each individual. As can be seen, for lotteries involving a relatively low chance of the Frixion pen, E(WTP) is generally above WTP - subjects are generally exhibiting risk aversion. However, for lotteries involving a higher chance of the Frixion Pen, the result is reversed and we see a statistically significant preponderance of individuals whose WTP exceeds E(WTP). This is true both for

\footnotetext{
12 This seems a reasonable test of preference stability given the nature of the goods $\mathrm{A}$ and $\mathrm{B}$, but formally if preferences are not separable, it is not irrational to prefer A1 over A2 while preferring A2B over A1B.
} 
the simple lotteries and for the lotteries involving bundles.

\section{INSERT TABLE 3 HERE}

\section{INSERT FIGURE 3 HERE}

\section{The Shape of Subjects' WTP functions.}

We now explore the individual data further. Figure 4 shows the WTP data plotted for three individual subjects who are broadly representative of the whole sample. The left hand column shows valuations for the lottery involving A1 and A2, while the right hand column is the lottery involving bundles. In each figure, the WTP for the different lotteries is plotted in red along with the expected value of WTP based on the answers to the two questions involving degenerate lotteries. The left hand side of each $\mathrm{x}$ axis represents the case where the probability of obtaining A2 is 1 , while the right hand extreme represents the case where the probability of obtaining A2 is zero. When the red line is above the blue line, the subject is risk loving; when the red line is below the blue, the subject is risk averse. In these figures we see different patterns. Subject 3 is consistent in valuing lotteries strictly less than the expected WTP. Subject 1 values the bundle lotteries almost in line with expected WTP, but values the lottery A1_A2 generally below the expected WTP. Subject 2 is extremely unusual in his or her responses and in the case of A1_A2 values the lottery more than either of the separate products in some instances and values the lottery at zero in other instances.

\section{INSERT FIGURE 4 HERE}

We classify subjects as risk loving, risk neutral or risk averse, using two methods (see Table 4). Method 1 is based on their response to the equal probabilities (1/1) lottery and method 2 as having a specific risk preference if at least three of her five WTP values lie on one side of the expected value line are directed to that specific risk preference. Table 4 shows that, in the values for lottery A1_A2, there is no common tendency across subjects to have a specific risk preference. In fact, two subjects (including subject 2 shown in Figure 4) have an S-shape WTP function, which means that they were apparently underweighting the small probabilities and overweighting the high probabilities of receiving A1. In the right hand columns, Table 4 also shows subjects' risk preferences for bundled lottery A1B_A2B. We found the results of the curvature of subjects' WTP functions and risk preferences for bundled lottery A1B_A2B to be similar to those for lottery A1_A2 although in this case there 
are no ' $\mathrm{S}$ ' shaped responses. Furthermore, the number of risk-seeking individuals in bundled lottery A1B_A2B is less frequent than the number of risk seeking individuals in lottery A1_A2. In other words, it does not suggest any additional effects from bundling on the distribution of risk-seeking individuals.

\section{INSERT TABLE 4 HERE}

As we have shown in Table 3, there is a common tendency to show more risk loving behavior for the lotteries involving a higher probability of winning the preferred good (using the bundle involving the Frixion pen). In some cases this means subjects actually place a higher value on the lottery than on either of its possible components. Table 5 documents the number of subjects who gave a higher WTP for the lottery compared to the WTP for either of the individual bundles or goods. The first column shows the odds in the lottery. The second column shows the number of subjects with a WTP for lottery A1_A2 that is at least as high as her maximum WTP for the individual product. Even at low odds, around 20\% of subjects give a valuation for the lottery that is at least as high as the maximum WTP for the individual product. In the final column the exercise is repeated for the bundled lottery A1B_A2B. We found the following stylized fact that is similar to our findings on single product lotteries: a significant number of subjects' WTP values for bundled lottery A1B_A2B are as high as their maximum WTP values for the individual bundle. Furthermore, for both single and bundled product lotteries, a majority of the subjects value $7 / 1$ lottery as much as they value the individual product or bundle.

As mentioned earlier, Gneezy et al, 2006 document an uncertainty effect in which a lottery is valued less than the minimum WTP of its components. We find a few such cases in our data though the numbers are much smaller than the number of cases where the lottery value exceeds the value of its possible components: for instance with the A1_A2 1/1 lottery only one subject has a WTP below that of the minimum WTP of the individual products while for the A1B_A2B 1/1 lottery, 8 subjects show such behavior.

\section{INSERT TABLE 5 HERE}

\section{Demand Curve.}


Recall that we are interested in whether selling goods in the form of lotteries is potentially more profitable than selling them separately and deterministically. Specifically, we wish to compare, for a given number of units of product $\mathrm{x}, \mathrm{m}_{\mathrm{x}}$ and a given number of units of product $\mathrm{z}, \mathrm{m}_{\mathrm{z}}$ whether more revenue can be obtained by selling the goods separately, or through a lottery in which the chance of winning $x$ is $p=\left(m_{x} /\left(m_{x}+m_{z}\right)\right)$ and the chance of obtaining $\mathrm{z}$ is 1-p. To do this we construct demand functions from the responses made by subjects. Since, for a given lottery and a price q, demand is given by the number of subjects who state wtp $\geq \mathrm{q}$ we can write $q\left(m_{x}\right)$, to define the inverse demand curve - in other words the price at which $\mathrm{m}_{\mathrm{x}}$ units of $\mathrm{x}$ would be sold. Similarly, $q\left(m_{z}\right)$, is the inverse demand curve for $\mathrm{z}$ and $q(p, 1-p, x, z)$ is the inverse demand curve for the lottery. Then, the seller can expect more revenue by using a lottery if,

$$
p * q\left(m_{x}\right)+(1-p) * q\left(m_{z}\right)<q(p, 1-p, x, z)
$$

Call the left-hand side of this equation the weighted inverse demand curve. Figure 5 shows plots for the product lottery's demand curve compared to the corresponding weighted inverse demand. It can be seen that in general there are not huge differences between the two curves in each panel. However, the curves for lottery A1_A2 suggests a significant difference in the actual and weighted demand curves for the 3/1 lottery and the $7 / 1$ lottery. On the other hand, in terms of bundled product lotteries (the right hand side of the figure), the significant difference is only for 7/1 bundled lottery. Both results suggest that negatively skewed product lotteries consistently produce larger demands than their weighted deterministic demands. In other words, selling negatively skewed product lotteries may produce higher profits for sellers than selling products in a deterministic way, since optimistic individuals may value a product lottery more highly than its expected value.

\section{INSERT FIGURE 5 HERE}

\section{Discussion}

In general, our valuation experimental results suggest that uncertainty has a negative effect on subjects' WTP. In other words, in keeping with the huge literature on lotteries involving money most subjects are risk averse for lotteries involving products. Yet, we found that a significant minority of subjects are risk-seeking when buying product lotteries and for some lotteries many individuals value the lottery as highly as they value the individual product with the highest valuation. Bundling makes little difference to this conclusion. 


\section{HYPOTHETICAL CHOICE QUESTIONNAIRE}

The experiment has the advantage of being incentivized. However, one worry is that the results might not apply to other contexts involving more valuable or more complex products. Consequently, we conducted two follow-up exercises with the subjects to see whether subjects had an appetite for product lotteries under different circumstances.

\section{Design}

The first follow-up was conducted as part of the conclusion to the incentivized experiment. Before the outcome of the experiment was revealed subjects were asked to fill in a paper-based choice experiment involving hypothetical scenarios. In each choice task, subjects had to choose one of the following three options: a certain product, its substitute, and a product lottery in which there is a $50 \%$ probability of receiving one of the products. There was no price attributed to each product in any of the choice tasks.

We chose paired goods from the same kind of product categories: pens, bundled pen and Kit Kat, smartphones, cameras, and notebooks. In particular, the pens are Pilot Frixion and Pentel Surari, the smartphones are Iphone 5S and Galaxy S5, the cameras are Canon 1DX and Nikon D4, and the notebooks are Toshiba PortegeZ930 and Lenovo IdeaPad U300s We deliberately chose high-end smartphones, cameras, and notebooks to ensure that most of the subjects would not already own the products at the time of the experiment. We did not provide any detailed information, although their pictures and exact names are clearly described in each of the choice tasks. In the case of pens and Kit Kat, these were the same goods as used in the main part of the experiment. As such subjects are assumed as having product knowledge and familiarity in the choice experiment. ${ }^{13}$ In terms of the treatment goods, we chose feature-rich electronic products, such as smartphones, cameras, and notebook computers - the sort of goods that might appear in a fukubukuro sale. One motive for these particular goods is provided by an abundant literature affirming the positive roles of information and familiarity in consumers' buying decisions (Swaminathan, 2003). Yet, for the consumers, being well-informed or familiar with a product that they intend to buy may

\footnotetext{
${ }^{13}$ We conducted the choice experiment before the outcome session in the valuation experiment. By doing so, subjects' choice behaviors would not be affected by their ownership of the experimental goods.
} 
not be an easy task. First, searching for product information is costly (Stigler, 1961), especially when an excessive amount of detailed information may be necessary for the consumer to comprehend a feature-rich electronic product. Second, experience is sometimes necessary for the consumer to gain knowledge of a product's features and functions (Bruck, 1985). Third, even if the information is available and costless to obtain, the consumer may experience an "information overload" that may produce a reverse effect on his or her intentions to buy (Jacoby, 1984; Eppler and Mengis, 2004). In this situation a consumer may prefer to avoid responsibility for making a final decision about purchase between competing products. For such consumers buying fukubukuro rather than one certain product is an optimal choice for the consumers. Smartphones, notebook computers and cameras may fall into this category of goods.

\section{Results}

Table 6 shows the frequency of the subjects who chose a product lottery. A few subjects missed or did not respond to a particular choice task so the sample size is not always 38. A very small number of subjects chose a product lottery of the pens though this is probably because most had expressed a clear preference for one pen brand in the previous experiment. On the other hand, many subjects chose a product lottery of the other goods. In the case of cameras for instance over $50 \%$ of subjects preferred the lottery to either of the products.

\section{INSERT TABLE 6 HERE}

In order to understand better the experimental results, we conducted an online short survey with subjects on the following four main criteria: degree of familiarity, degree of knowledge, degree of attractiveness, and perceived quality (see example from the questionnaire in the Appendix).The survey took place 3 months after the experiment. From the 38 subjects who participated in the choice experiment, we received 28 responses (17 males and 11 females). Figure 6 shows the average of subjects' responses to the four criteria for each product. Subjects are more familiar with and knowledgeable about the Frixion and Surari pens than the other products, except for Iphone 5S and Galaxy S5. This is not peculiar since the two smartphones are famous among young people and have been advertised and broadcasted massively in the media. The pens, on the other hand, are Japanese, rarely 
available in the Indonesia market, and newly introduced to the subjects during the experiments. However, as the average product knowledge of the pens is higher than that of the smartphones, it seems that being familiar with a product does not necessarily mean being knowledgeable about it.

In terms of the degree of attractiveness and the perceived quality, it is only for pens that subjects attribute strong attractiveness and perceived quality to one brand. For smartphones, cameras, and notebooks, subjects attribute relatively equal attractiveness and perceived quality. It is possible that when a product's detailed information is not available or when the experience with a product is not feasible, subjects assess the product's attractiveness and quality based on their general perceptions, which may be similar across brands.

\section{INSERT FIGURE 6 HERE}

To examine the process of choice further, we used the following logistic regression model to measure the effects of information and risk preference on subjects' lottery choices:

$$
\begin{gathered}
\text { lotterychoice }= \\
\alpha_{0}+\alpha_{1} \text { riskpreference }+\alpha_{2} \text { gender }+\alpha_{3} \text { less_knowledge }+\alpha_{4} \text { unfamiliar } \\
+\alpha_{5} \text { leaningattractiveness }+\alpha_{6} \text { leaningquality }+\varepsilon
\end{gathered}
$$

A description of the variables is as follows:

Lottery choice: $1=$ chose thelottery and $0=\operatorname{did}$ not choose a lottery

Risk preference: ${ }^{14} 1=$ risk-averse, $2=$ risk-neutral, and $3=$ risk-seeking

Gender: $1=$ male and $0=$ female

Less knowledge: subjects' degree of knowledge of products' features and functions. We classified subjects as having less product knowledge if they answered "less knowledge" or "no knowledge at all" to the questions on their degree of knowledge of the products' features and functions.

\footnotetext{
${ }^{14}$ According to the classification used in the incentivized experiment.
} 
Unfamiliarity: subjects' degree of familiarity with the products. If subjects answered "less familiar" or "not familiar at all" to the questions on their familiarity with the products, then we classified them as being unfamiliar with the products.

Lean_attractiveness: subjects who have a strong interest in one product above another product in a specific product category. We classified subjects as having a leaning towards one of the two products if their responses to the attractiveness questions on the two products are different by at least two points on the Likert scale.

Lean_quality: subjects who see a higher perceived quality in one product above another product in a specific product category. We classified subjects as having a leaning quality perception of two products if their responses to the perceived quality questions on the two products are different by at least two points on the Likert scale.

Dummy_2: dummy variable for bundled pen and Kit Kat

Dummy_3: dummy variable for smartphones

Dummy_4: dummy variable for cameras

Dummy_5: dummy variable for notebooks

Dummy_treat: dummy variable for the non-experiment goods: smartphones, cameras, and notebooks; $1=$ non-experiment goods, $0=$ experimental goods.

rp*dum_treat: interaction variable between risk preference and dummy treatment

Although we do not have strong priors on the sign of the variables, we conjecture the following relations: $\alpha_{1}>0 ; \alpha_{2}>0^{15} ; \alpha_{3}>0 ; \alpha_{4}>0 ; \alpha_{5}<0$; and $\alpha_{6}<0$.

\section{INSERT TABLE 7 HERE}

Table 7 shows that the variables of less knowledge and unfamiliarity significantly affect subjects' lottery choices. In model 5 , in which we introduced dummy variables, less knowledge becomes insignificant. This may be because the effect of this variable is very much represented by the effect of the dummy variables. Meanwhile, familiarity seems robust as a positive determinant of subjects' lottery choices. Furthermore, positively significant

\footnotetext{
${ }^{15}$ Croson and Gneezy 2009) suggest that women are more risk-averse than men.
} 
coefficients for the dummy variables for smartphones, cameras, and notebooks suggest that subjects are more likely to choose a lottery of these products compared to the lottery of pens or the bundled lottery of pen and Kit Kat. We may conclude that subjects who are less informed or unfamiliar with the products have a greater chance of choosing product lotteries. Although the coefficient on risk preference in the experiment is positive it is not significant at the $10 \%$ level in any specification. Similarly, gender, lean_attractiveness, and lean_quality seem to not have an effect on subjects' lottery choices.

As aforementioned, the absence of price attributes in the choice tasks may undermine the role of risk-seeking in the lottery choice of control goods. On the other hand, uncertainty towards the value of deterministic products in the treatment goods may magnify the role of risk preference. Therefore, we conducted estimations only on the risk preference for treatment goods. In model 4, we re-estimated model 3 by introducing the interaction variable between risk preference and dummy_treatment $\left(r p^{*} d u m_{-}\right.$treat). The results suggest that risk preference is indeed significant in affecting subjects' lottery choices of treatment goods. ${ }^{16}$

Furthermore, we expected that differences in the attractiveness and perceived quality of goods would produce a negative effect on subjects' lottery choices; however, our data show otherwise. There is even a positive, albeit insignificant, coefficient for diff_attractiveness. It is possible that we have unreliable or inaccurate data on these variables for two reasons: first, the survey was conducted three months after the choice experiment and second, subjects' assessments of perceived quality and attractiveness are trivial when the subjects are less informed and unfamiliar with the products.

\section{Discussion}

We conducted a hypothetical choice experiment to determine individuals' likelihoods of choosing product lotteries in various information settings. We used simple products from our experiment as well as complex and less familiar products. We found that a significant number of subjects chose product lotteries of the complex goods, compared to those who chose lotteries of the experiment goods.

\footnotetext{
${ }^{16}$ We produced consistent results from model 4 when we used rp_1 and rp_5 in rp*dum_treat.
} 


\section{GENERAL DISCUSSION}

Incentivized risk preference studies have very seldom been conducted in the context of non-monetary prizes. Our study helps fill this gap by conducting within-subject experiments on individuals' WTP and choices for lotteries of consumer goods. There are four main findings: first, in general, risk has a negative effect on subjects' WTP; but within this, second, a considerable number of subjects are risk-seeking; third, a significant minority of subjects are willing to pay more for a lottery than they are for individual components, especially when buying negatively skewed product lotteries; and fourth, a risk-seeking preference and familiarity with and knowledge about products have significant effects on subjects' risky choice behaviors.

On the other hand bundling does not seem to have an effect on risk attitudes per se, though it does reduce the coefficient of variation (standard deviation/mean WTP) (see Table 3 ) and this might make pricing easier for the seller. It is also worth noting that, at least for our goods, we do not see much evidence of an uncertainty effect as found by Gneezy et al, 2006. In fact quite the opposite.

In a monetary domain, prospect theory describes individuals' tendencies to overweight the small probability of winning a large prize (Tversky and Kahneman, 1992). Our experiment is compatible with a world in which most subjects tend to overweight the high, rather than the small, probabilities of receiving a more preferable product.

Our fourth finding is derived from our choice experiment. Subjects who have less knowledge about and familiarity with the goods are more likely to choose product lotteries. One possible interpretation of these results is that unfamiliarity and complexity of options may trigger subjects' indecisiveness. Therefore, fukubukuro may provide a simple and direct solution for the subjects who are indecisive. Although some psychological and experimental studies have related indecisiveness to risk aversion (Danan and Ziegelmeyer, 2006; Potworowski, 2010), our finding do not particularly support this explanation.

This experiment has provided an important step towards understanding risk attitudes for lotteries involving goods. At the same time the experiment and the follow-up survey on hypothetical choices leaves unresolved the exact reason why fukubukuro might be a 
profitable strategy for retailers. Generally our results suggest that risk attitudes may play some role but may not be the core motive. Broadly speaking this leaves three kinds of reasons as possible explanations that require further research.

The first class of reason is strategic: selling goods through a lottery means that the last customer in the store faces the same choice set as the first. As a result, a firm that uses a lottery minimizes the risk that it will set prices too high for some goods that turn out to be valued lowly by consumers. The second possible reason is social: for instance buying using lotteries may stoke up buying frenzies. A third kind of reason is linked to the results of the hypothetical survey: some consumers may find lotteries attractive when they are feeling indecisive. This may be particularly the case if they are reluctant to take responsibility for making a positive decision in favor of one option that later turns out to be inferior to the option not chosen.

\section{References}

Anderson, C.K. and Xie, X. 2012, A Choice Based Dynamic Programming Approach for Setting Opaque Prices, Production and Operations Management, 21(3), 590-605.

Benzion, Uri, Shosh Shahrabani, and Tal Shavit, 2013, Retesting the Uncertainty Effect Using Lotteries with Real Products and Money, Bulletin of Economic Research 65, s1: s175-s186.

Bernheim, Douglas. 1994, A Theory of Conformity, Journal of Political Economy, 102(5), 841-877.

Bohm, Peter, and Hans Lind, 1993, Preference reversal, real-world lotteries, and lottery-interested subjects. Journal of Economic Behavior \& Organization 22, no. 3: 327-348.

Bruck, M. 1985, The effect of product class knowledge on information search behavior, Journal of Consumer Research, 12(1), 1-6.

Caplin, Andrew and Leahy, John, 2001, Psychological Expected Utility Theory and Anticipatory Feelings, The Quarterly Journal of Economics, 116(1), 55-79.

Conlisk, John. 1993, The Utility of Gambling. Journal of Risk and Uncertainty, 6, 
$255-275$.

Croson, Rachel and Uri Gneezy. 2009, Gender differences in preferences. Journal of Economic Literature, 47(2), 1-27.

Danan, E. and Ziegelmeyer, A. 2006, Are preferences complete? An experimental measurement of indecisiveness under risk, Papers on Strategic Interaction 2006-01, Max Planck Institute of Economics, Strategic Interaction Group.

Deck, C., and Schlesinger, H. 2012, Consistency of Higher Order Risk Preferences. CESifo Working Paper Series 4047, CESifo Group Munich.

Dittmar, Helga, and John Drury, 2000, Self-image-is it in the bag? A qualitative comparison between "ordinary" and "excessive" consumers, Journal of Economic Psychology 21, no. 2: 109-142.

Dohmen, Thomas, Armin Falk, David Huffman, Uwe Sunde, Jürgen Schupp, and Gert G. Wagner. 2011, Individual risk attitudes: Measurement, determinants, and behavioral consequences. Journal of the European Economic Association 9.3: 522-550.

Drichoutis, Andreas C., Rodolfo M. Nayga, Jayson L. Lusk, and Panagiotis Lazaridis, 2012, When a risky prospect is valued more than its best possible outcome, Judgment and Decision Making 7, no. 1.

Einav, Liran, Amy Finkelstein, Iuliana Pascu, and Mark R. Cullen, 2012, How General Are Risk Preferences? Choices under Uncertainty in Different Domains, The American Economic Review 102, no. 6: 2606-2638.

Eppler, J.M., and Mengis, J. 2004, The concept of information overload: A review of literature from organization science, accounting, marketing, MIS, and related disciplines, The Information Society, 20, 325-344.

Fischbacher, U., 2007, z-Tree: Zurich toolbox for ready-made economic experiments, Experimental economics, 10(2), pp.171-178.

Gneezy, U., List, J. A., and Wu, G. 2006, The Uncertainty Effect: When a Risky Prospect is Valued Less Than Its Worst Outcome, Quarterly Journal of Economics, 121, 1283-1309. 
Goldsmith, K. and Amir, On. 2010, Can Uncertainty Improve Promotion? Journal of Marketing Research, December, 1070-1077.

Hamman, J. R., Loewenstein, G., Weber, R. A. 2010, Self-Interest through Delegation: An Additional Rationale for the Principal-Agent Relationship, American Economic Review, 100, 1826-1846.

Harrison, G. W., List, J., \& Towe, C. 2007, Naturally Occurring Preferences and Exogenous Laboratory Experiments: A Case Study of Risk Aversion, Econometrica, 75, 433458.

Harrison, G.W., R.M. Harstad and E.E. Rutström. 2004, Experimental Methods and Elicitation of Values, Experimental Economics, 7(2), 123-140.

Hey, J.D. 1984, The economics of optimism and pessimism: a definition and some applications, Kyklos 37,181-205.

Jacoby.J. 1984, Perspectives on information overload, Journal of Consumer Research, $10(4), 432-436$.

Lönnqvist, Jan-Erik, Markku Verkasalo, GariWalkowitz, and Philipp C. Wichardt. 2015, Measuring individual risk attitudes in the lab: Task or ask? An empirical comparison, Journal of Economic Behavior and Organization 119: 254-266.

Palfrey, Thomas R., 1983, Bundling decisions by a multiproduct monopolist with incomplete information. Econometrica, 463-483.

Potworowski, G. A. 2010, Varieties of Indecisive Experience: Explaining the Tendency to Not Make Timely and Stable Decisions. Ph.D. Thesis, the University of Michigan.

Riddel, Mary. 2012, Comparing risk preferences over financial and environmental lotteries, Journal of Risk and Uncertainty 45.2 135-157.

Starmer, Chris, 2000, Developments in non-expected utility theory: The hunt for a descriptive theory of choice under risk, Journal of Economic Literature， 38, $2 \quad 332-382$

Stigler, George J. 1961, The Economics of Information, Journal of Political Economy, 69(3), 213-225. 
Swaminathan,V. 2003, The Impact of Recommendation agents on Consumer Evaluation and Choice: The Moderating Role of Category Risk, Product Complexity, and Consumer Knowledge. Journal of Consumer Psychology, 13(1), 93-101.

Tal, Shavit, Benzion Uri, and Shahrabani Shosh, 2010, Risk attitude in lotteries offering real products and monetary outcomes, International Journal of Economic Theory 6, $2,253-261$.

Tversky, A. and Kahneman, D. 1992, Advances in Prospect Theory: Cumulative Representation of Uncertainty, Journal of Risk and Uncertainty, 5, 297-323.

Weber, Elke U., Ann-Renee Blais, and Nancy E. Betz, 2002, A domain-specific riskattitude scale: measuring risk perceptions and risk behaviors, Journal of Behavioral Decision Making 15, 4, 263. 
Figure 1. Yodobashi Camera: Digital Compact Camera.

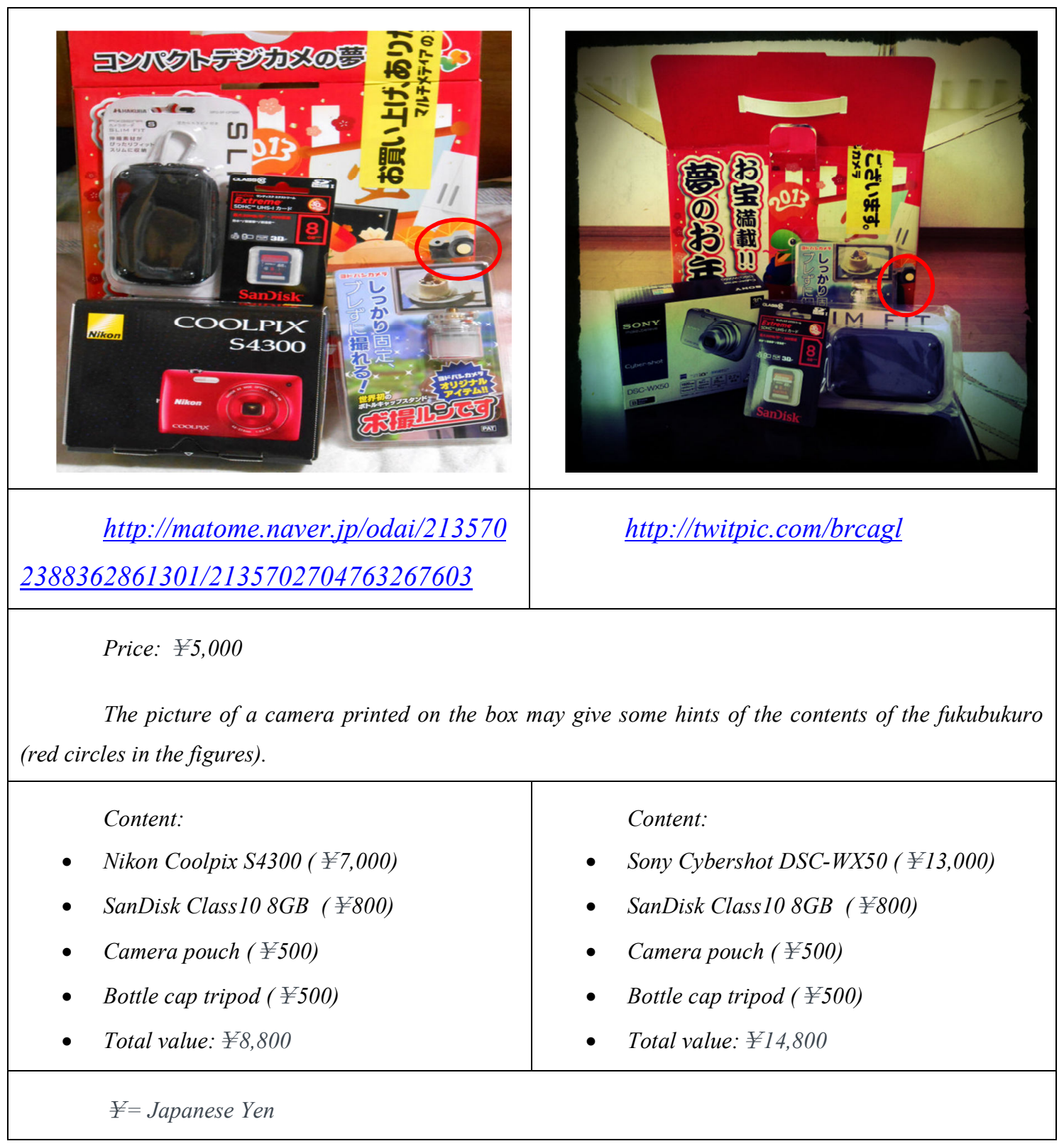


Figure 2. Brand Retailer: Apple's Fukubukuro.

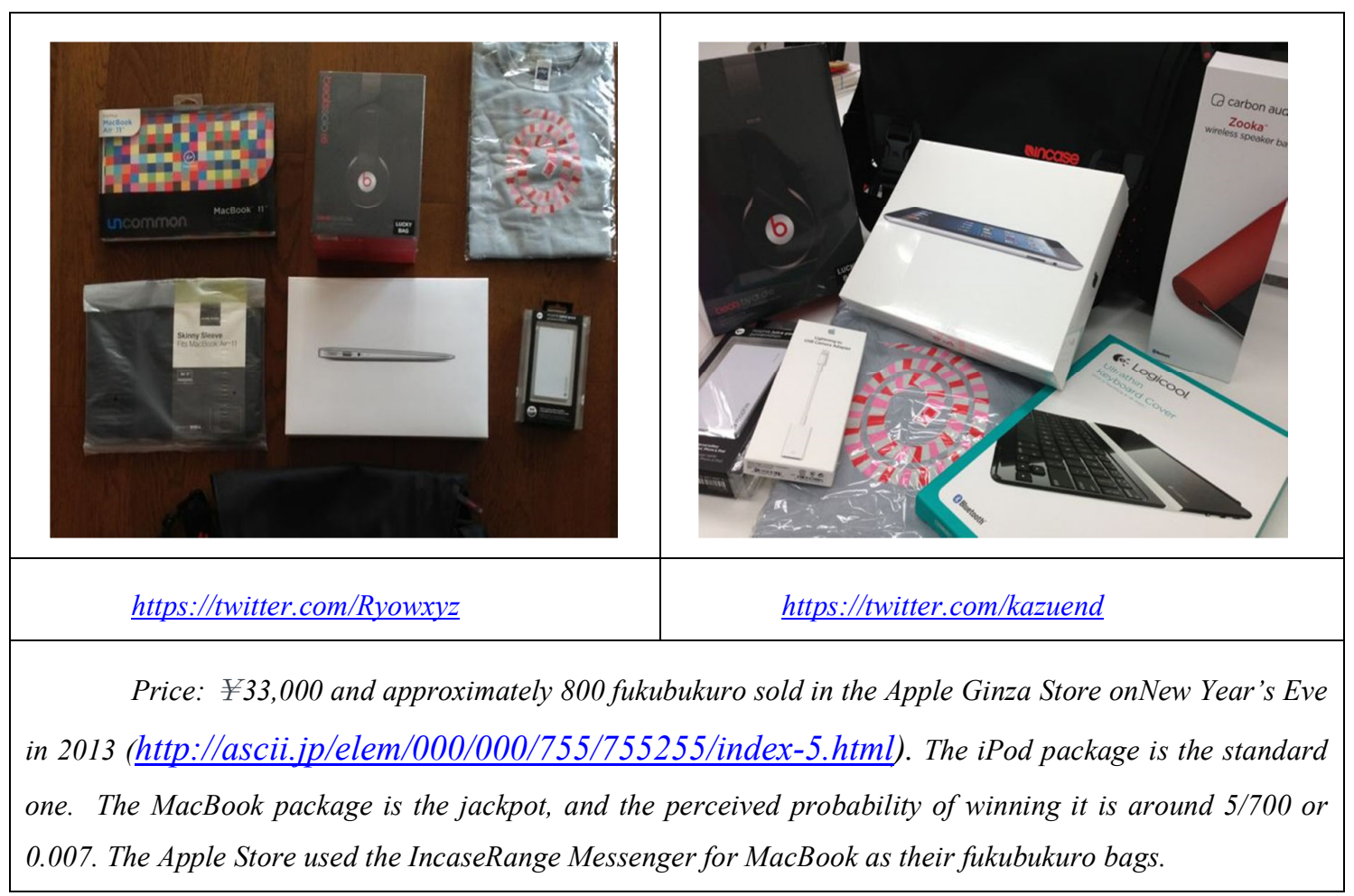


Figure 3. Distribution of WTP Responses.

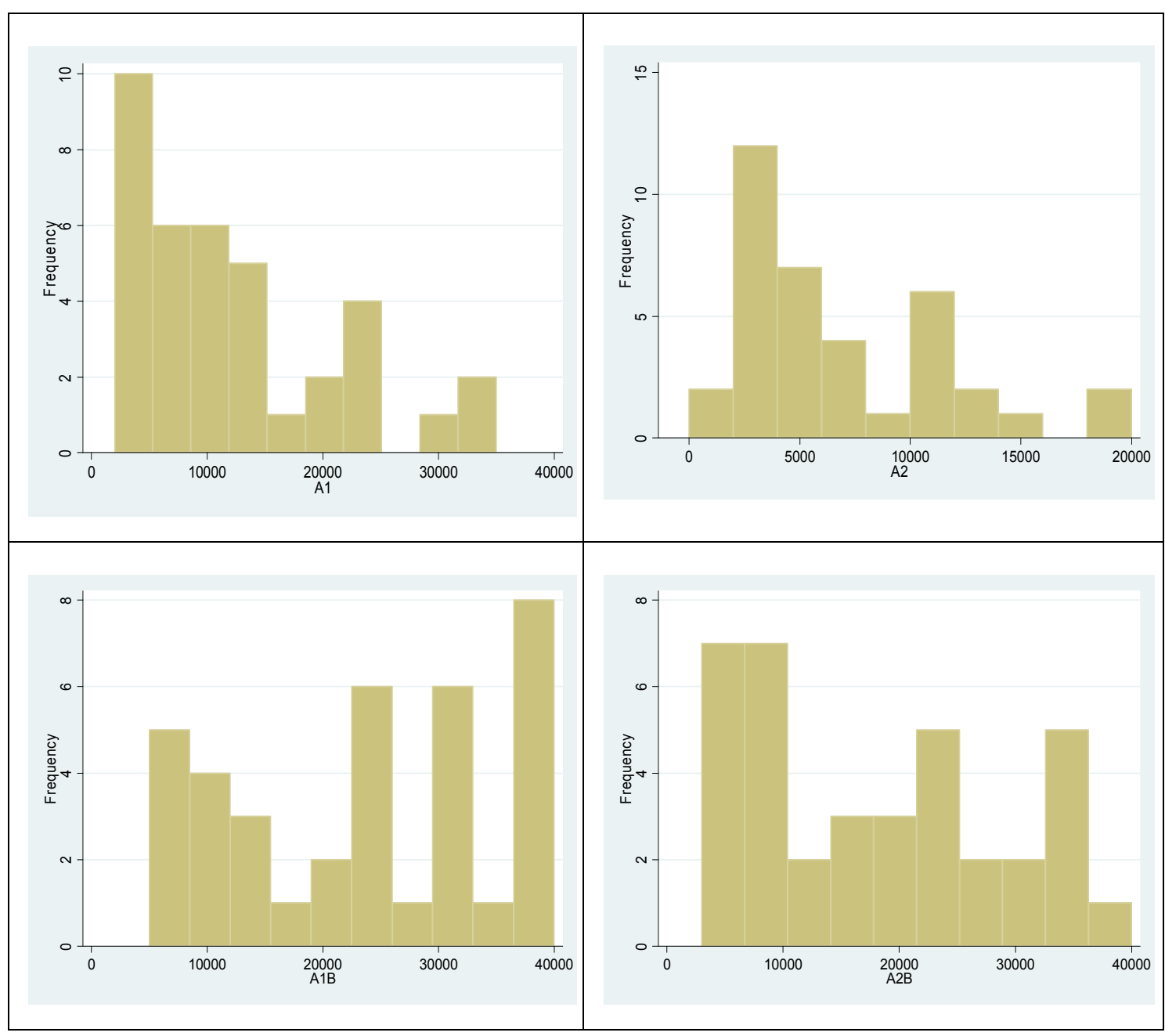


Figure 4. Individual WTP from 3 subjects.

Lottery $A 1 \_A 2$
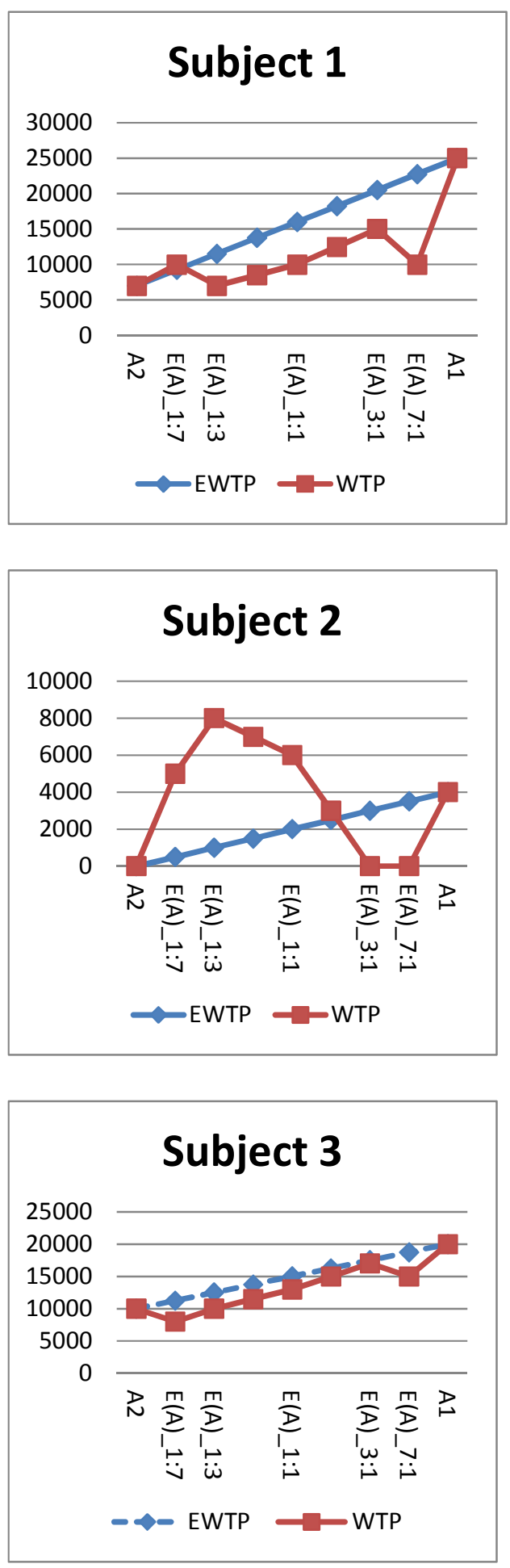

Lottery $A 1 B \_A 2 B$
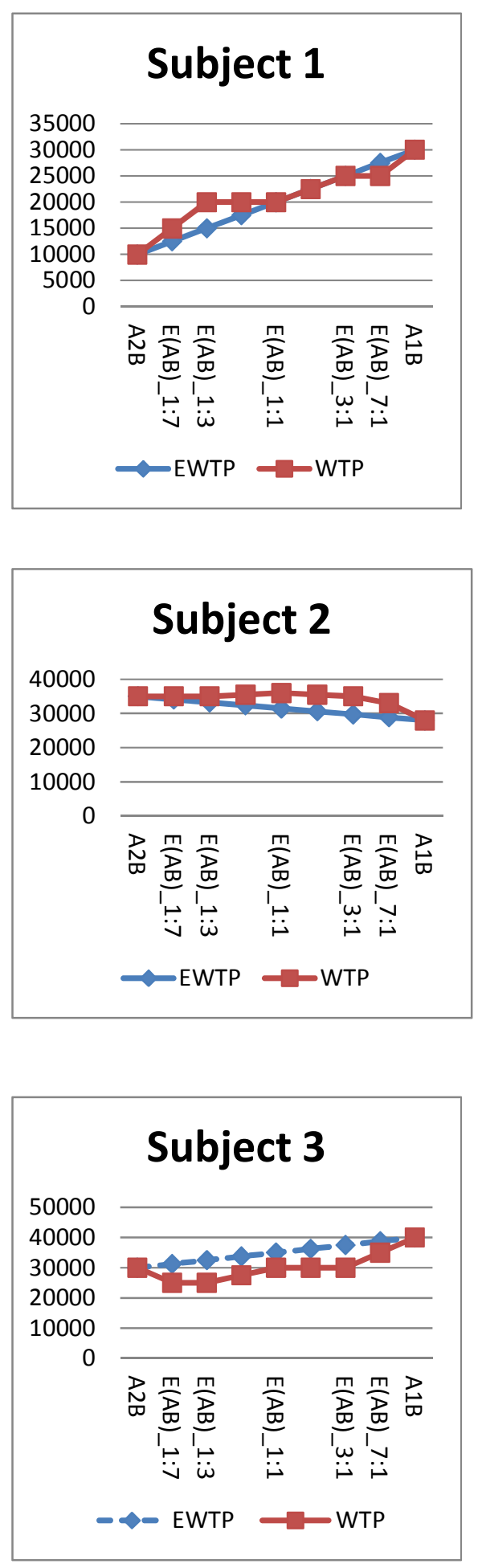
Figure 5. Demand Curves.

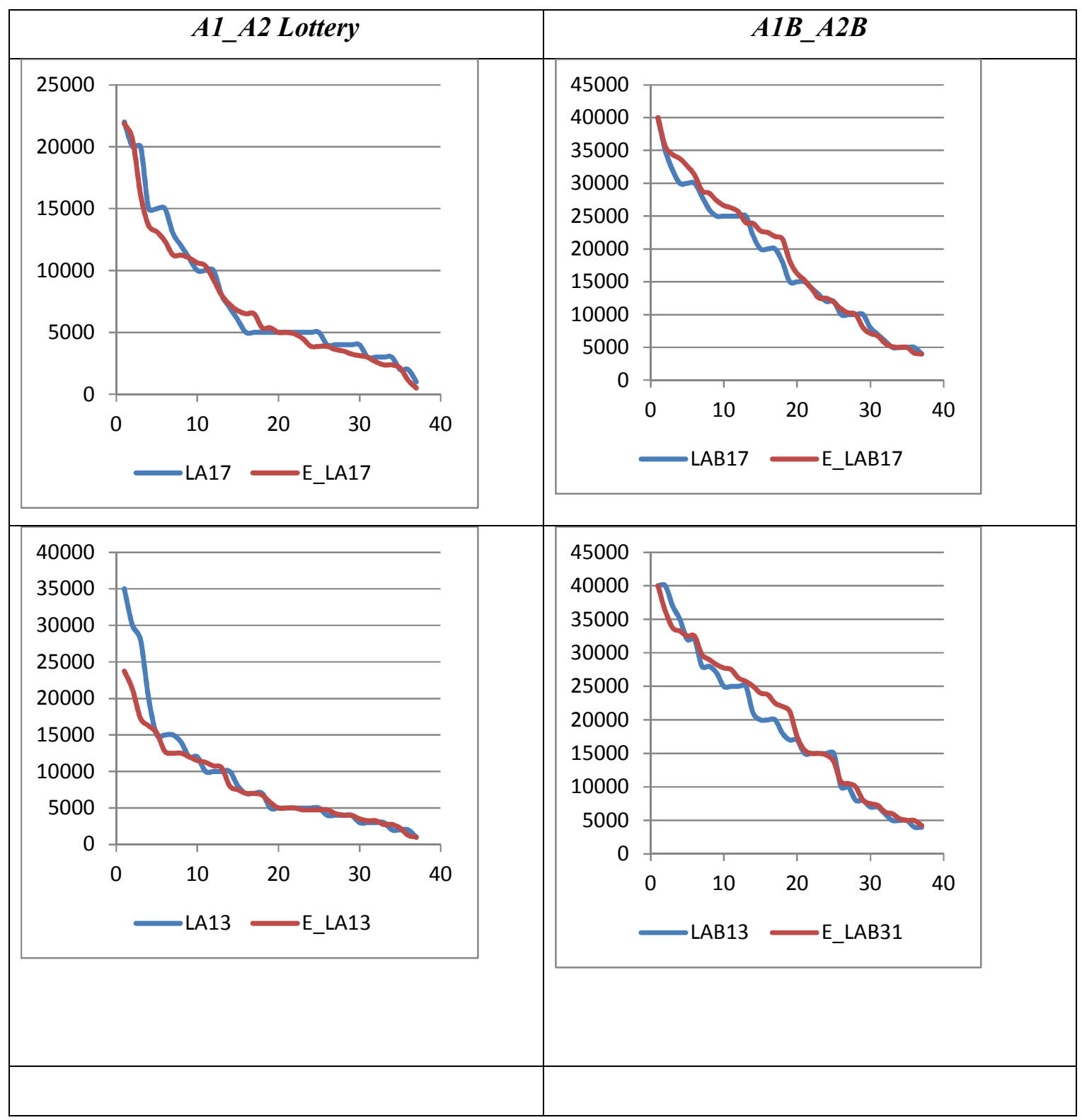




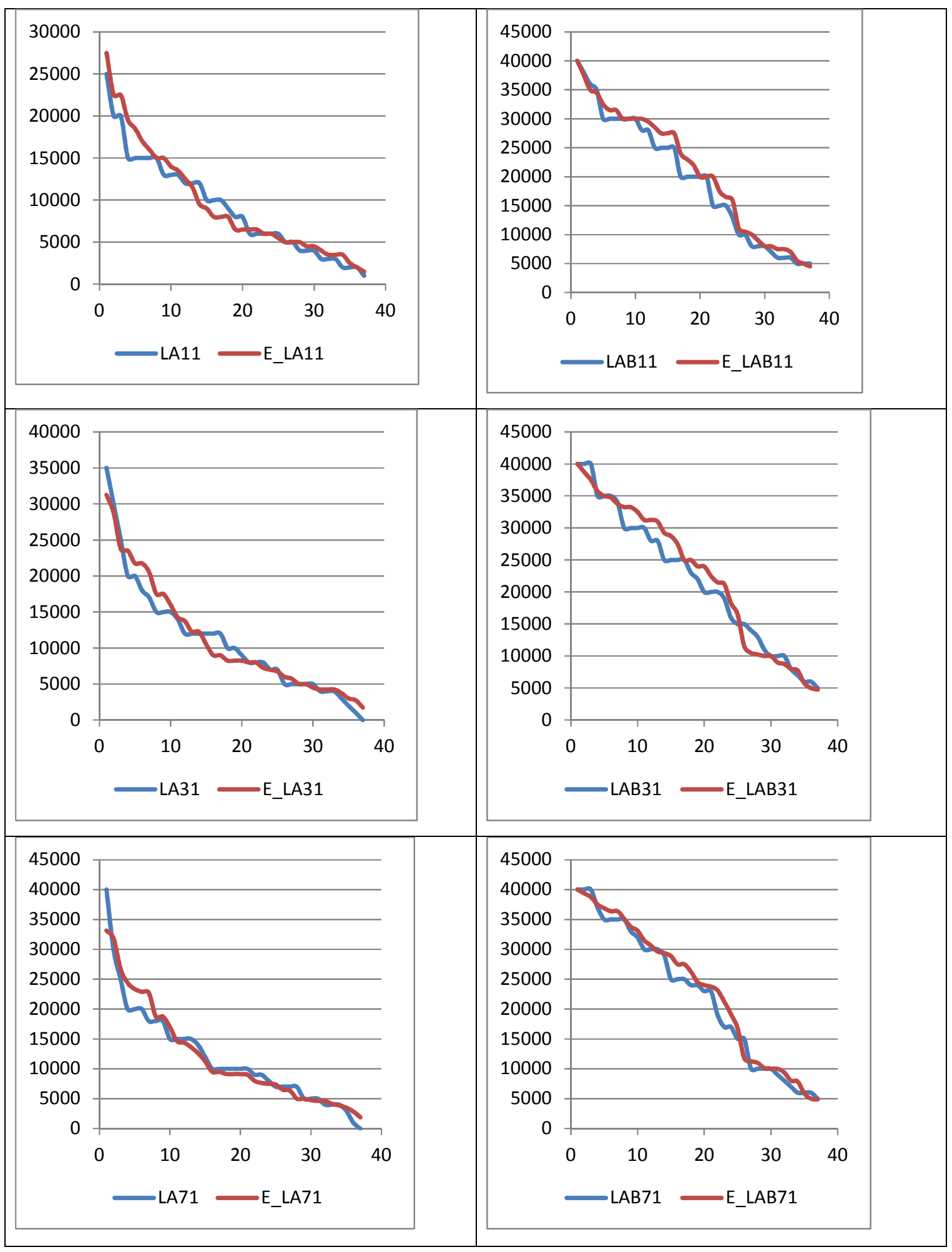


Figure 6. Average of Subjects' Assessment Responses.

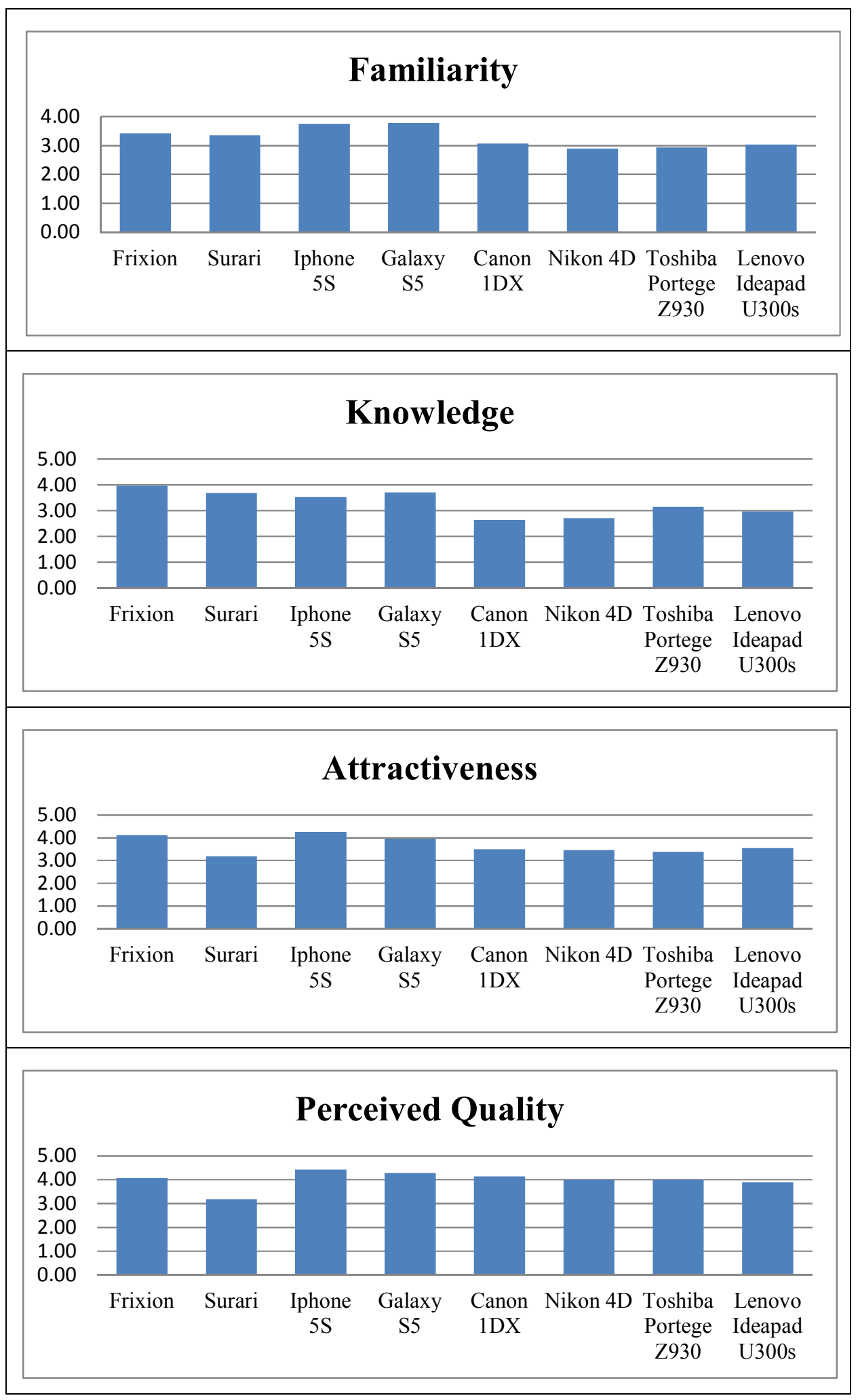


Table 1. Product Features and 15 Tasks.

\begin{tabular}{|c|c|c|}
\hline Task & Product Category & Scenario \\
\hline 1 & $\mathrm{~A} 1$ & Deterministic \\
\hline 2 & $\mathrm{~A} 2$ & Deterministic \\
\hline 3 & B & Deterministic \\
\hline $4-8$ & Lottery A1_A2 & $\begin{array}{lllll}1 / 7 & 1 / 3 & 1 / 1 & 3 / 1 & 7 / 1\end{array}$ \\
\hline 9 & A1B & Deterministic \\
\hline 10 & $\mathrm{~A} 2 \mathrm{~B}$ & Deterministic \\
\hline $11-15$ & Lottery A1B_A2B & $\begin{array}{lllll}1 / 7 & 1 / 3 & 1 / 1 & 3 / 1 & 7 / 1\end{array}$ \\
\hline
\end{tabular}

Table 2. Test of Monotonicity ( $\mathrm{n}=37)$.

\begin{tabular}{ccccc}
\hline Variable & $\mathrm{N}(+)$ & $\mathrm{N}(0)$ & Prob. & Conclusion \\
\hline A1B vs. A1 & 35 & 2 & 0.0000 & SM \\
A1B vs. B & 27 & 3 & 0.0002 & SM \\
A2B vs. A2 & 36 & 1 & 0.0000 & SM \\
A2B vs. B & 20 & 4 & 0.2291 & WM
\end{tabular}

Note: $(+)$ the value of the bundle is higher than the value of the individual goods.

W/SM represents "Weak/Strong Monotonic Preference." 
Table 3. Summary Statistics of Subjects' WTP Responses.

\begin{tabular}{|c|c|c|c|c|c|c|}
\hline \multirow[b]{2}{*}{ Good } & \multicolumn{6}{|c|}{ Coefficient } \\
\hline & Mean & E(WTP) & Median & variation & $\mathrm{N}$ & Sign test $(z)$ \\
\hline Surari Pen (A2) & 6,378 & 6378 & 4,890 & 0.77 & 37 & \\
\hline 1/7 lottery of A1_A2 & 7,595 & 7186 & 5,485 & 0.72 & 37 & $-4.38 * * *$ \\
\hline 1/3 lottery of A1_A2 & 9,054 & 7993 & 8,052 & 0.89 & 37 & $-2.84 * * *$ \\
\hline 1/1 lottery of A1_A2 & 9,135 & 9608 & 5,841 & 0.64 & 37 & -1.30 \\
\hline 3/1 lottery of A1_A2 & 10,973 & 11223 & 7,819 & 0.71 & 37 & $4.4 * * *$ \\
\hline 7/1 lottery of A1_A2 & 11,892 & 12030 & 8,266 & 0.70 & 37 & $4.94 * * *$ \\
\hline Frixion Pen (A1) & 12,838 & 12838 & 9,060 & 0.71 & 37 & \\
\hline Kit Kat (B) & 17,081 & 17,081 & 10,210 & 0.60 & 37 & \\
\hline Surari and Kit Kat (A2B) & 18,324 & 18324 & 11,240 & 0.61 & 37 & \\
\hline 1:7 lottery of A1B_A2B & 17,757 & 18983 & 9,816 & 0.55 & 37 & $-3.600 * * *$ \\
\hline 1/3 lottery of A1B_A2B & 18,541 & 19642 & 10,746 & 0.58 & 37 & $-3.371 * * *$ \\
\hline 1/1 lottery of A1B_A2B & 19,649 & 20959 & 10,822 & 0.55 & 37 & -0.779 \\
\hline 3/1 lottery of A1B_A2B & 21,757 & 22277 & 10,621 & 0.49 & 37 & $1.72 *$ \\
\hline 7/1 lottery of A1B_A2B & 22,162 & 22936 & 24,000 & 0.52 & 37 & $3.17 * * *$ \\
\hline Frixion and Kit Kat (A1B) & 23,595 & 23595 & 25,000 & 0.50 & 37 & \\
\hline
\end{tabular}

Sign test: z-score for matched pairs test of equality between WTP and E(WTP). A - sign means a preponderance of pairs where $\mathrm{WTP}<\mathrm{E}(\mathrm{WTP}) . * * *=$ significant at $1 \%$ level; $*=$ significant at $10 \%$ level.

Table 4.Risk Preferences

\begin{tabular}{lcccc}
\hline & \multicolumn{2}{c}{$\begin{array}{c}\text { A1_A2 } \\
\text { Based on }\end{array}$} & \multicolumn{2}{c}{$\begin{array}{c}\text { A1B_A2B } \\
\text { Based on }\end{array}$} \\
Risk Preference & $1 / 1$ & 3 out of 5 & $1 / 1$ & 3 out of 5 \\
\hline Risk-Averse & 15 & 15 & 17 & 16 \\
Risk-Neutral & 8 & 7 & 8 & 4 \\
Risk-Seeking & 14 & 12 & 12 & 13 \\
S-Shape & -- & 3 & -- & -- \\
Undetermined & -- & - & -- & 4 \\
\hline
\end{tabular}


Table 5. Number of Subjects who Value Lottery As Much As They Value Preferred Product

\begin{tabular}{ccc}
\hline Lottery & $\mathrm{wtp}\left(\mathrm{A} 1 \_\mathrm{A} 2\right) \geq \max (\mathrm{wtp}(\mathrm{A} 1), \mathrm{wtp}(\mathrm{A} 2))$ & $\mathrm{wtp}\left(\mathrm{A} 1 \mathrm{~B} \_\mathrm{A} 2 \mathrm{~B}\right) \geq \max (\mathrm{wtp}(\mathrm{A} 1 \mathrm{~B}), \mathrm{wtp}(\mathrm{A} 2 \mathrm{~B}))$ \\
\hline $1 / 7$ & 7 & 9 \\
$1 / 3$ & 10 & 10 \\
$1 / 1$ & 10 & 14 \\
$3 / 1$ & 16 & 18 \\
$7 / 1$ & 23 & 18 \\
\hline
\end{tabular}

Table 6. Number of Subjects who Chose a Product Lottery.

\begin{tabular}{lcc}
\hline \multicolumn{1}{c}{ Product Category } & Freq. & N \\
\hline Frixion Pen vs. Surari Pen & 1 & 37 \\
Frixion\&Kit Kat vs. Surari\&Kit Kat & 3 & 37 \\
Iphone 5S vs. Galaxy S5 & 11 & 38 \\
Canon 1DX vs. Nikon D4 & 19 & 36 \\
Toshiba PortegeZ930 vs. Lenovo IdeaPad U300s & 15 & 36 \\
\hline
\end{tabular}


Table 7. Logistic Regression Test on Determinants of Lottery Choice.

\begin{tabular}{|c|c|c|c|c|c|}
\hline lottery choice & model 1 & model 2 & model 3 & model 4 & model 5 \\
\hline Risk preference & $\begin{array}{c}0.025 \\
(0.234)\end{array}$ & $\begin{array}{c}0.186 \\
(0.226)\end{array}$ & $\begin{array}{c}0.308 \\
(0.329)\end{array}$ & -- & $\begin{array}{c}0.480 \\
(0.367)\end{array}$ \\
\hline Gender & $\begin{array}{c}0.519 \\
(0.446)\end{array}$ & $\begin{array}{c}0.500 \\
(0.446)\end{array}$ & $\begin{array}{c}0.511 \\
(0.446)\end{array}$ & $\begin{array}{c}0.339 \\
(0.489)\end{array}$ & $\begin{array}{c}0.300 \\
(0.491)\end{array}$ \\
\hline Less knowledge & $\begin{array}{c}1.501 * * * \\
(0.550)\end{array}$ & $\begin{array}{c}1.475^{* * *} * \\
(0.546)\end{array}$ & $\begin{array}{c}1.556^{* * *} \\
(0.552)\end{array}$ & $\begin{array}{l}1.161 * * \\
(0.587)\end{array}$ & $\begin{array}{c}0.733 \\
(0.645)\end{array}$ \\
\hline Unfamiliarity & $\begin{array}{c}1.209^{* *} \\
(0.502)\end{array}$ & $\begin{array}{l}1.198 * * \\
(0.501)\end{array}$ & $\begin{array}{c}1.209 * * \\
(0.502)\end{array}$ & $\begin{array}{c}1.324 * * \\
(0.554)\end{array}$ & $\begin{array}{c}1.167 * * \\
(0.596)\end{array}$ \\
\hline Lean_attractiveness & $\begin{array}{c}0.013 \\
(0.853)\end{array}$ & $\begin{array}{c}0.005 \\
(0.860)\end{array}$ & $\begin{array}{c}0.062 \\
(0.856)\end{array}$ & $\begin{array}{c}0.598 \\
(0.591)\end{array}$ & $\begin{array}{c}0.968 \\
(1.085)\end{array}$ \\
\hline Lean_quality & $\begin{array}{l}-1.349 \\
(0.571)\end{array}$ & $\begin{array}{l}-1.400 \\
(1.155)\end{array}$ & $\begin{array}{l}-1.342 \\
(1.145)\end{array}$ & $\begin{array}{l}-1.238 \\
(1.241)\end{array}$ & $\begin{array}{l}-0.884 \\
(1.365)\end{array}$ \\
\hline Dummy_2 & -- & -- & -- & -- & $\begin{array}{c}1.385 \\
(5.108)\end{array}$ \\
\hline Dummy_3 & -- & -- & -- & -- & $\begin{array}{c}2.898 * * \\
(1.188)\end{array}$ \\
\hline Dummy_4 & -- & -- & -- & -- & $\begin{array}{c}3.737 * * * \\
(1.214)\end{array}$ \\
\hline Dummy_5 & -- & -- & -- & -- & $\begin{array}{c}3.138 * * * \\
(1.159)\end{array}$ \\
\hline $\mathrm{RP} *$ dum_treat & -- & -- & -- & $\begin{array}{c}1.035 * * * \\
(0.244)\end{array}$ & $\begin{array}{l}-- \\
--\end{array}$ \\
\hline Constant & $\begin{array}{c}-1.573 * * * \\
(0.571)\end{array}$ & $\begin{array}{c}-1.890 * * * \\
(0.607)\end{array}$ & $\begin{array}{c}-2.132 * * * \\
(0.779)\end{array}$ & $\begin{array}{c}-2.811 * * * \\
(0.579)\end{array}$ & $\begin{array}{c}-4.825^{* * *} \\
(1.404)\end{array}$ \\
\hline $\mathrm{N}$ & 131 & 131 & 131 & 131 & 131 \\
\hline Prob > chi2 & 0.0081 & 0.0062 & 0.0058 & 0.0000 & 0.0000 \\
\hline
\end{tabular}


Appendix.Example Screenshots, Goods Used and Instructions (English version).

N.B. Actual instructions and screens were in Indonesian.A full copy of the English language instructions is available on request from the authors.

\section{The example of task valuation of product lottery}

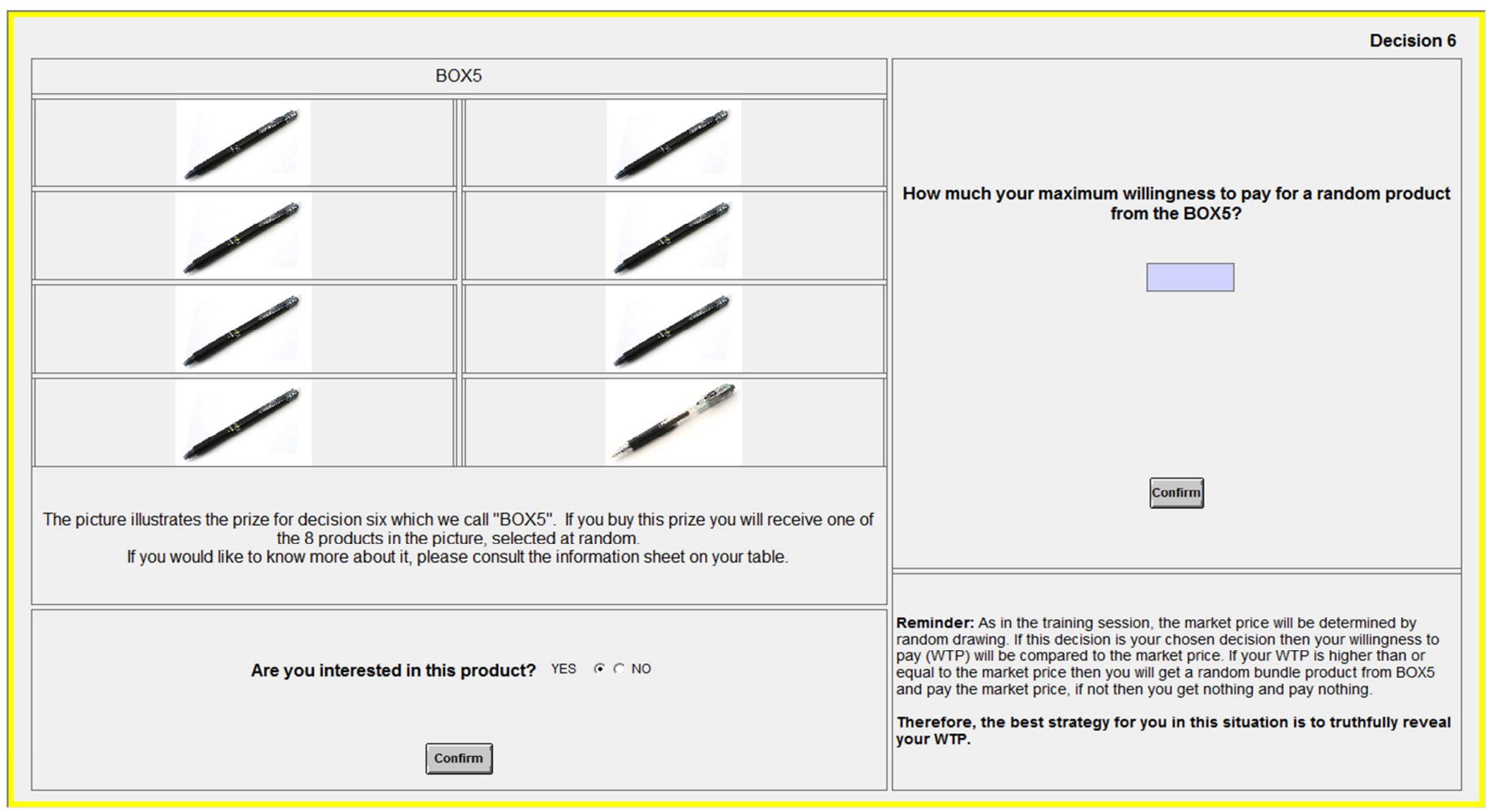




\section{Goods Used.}

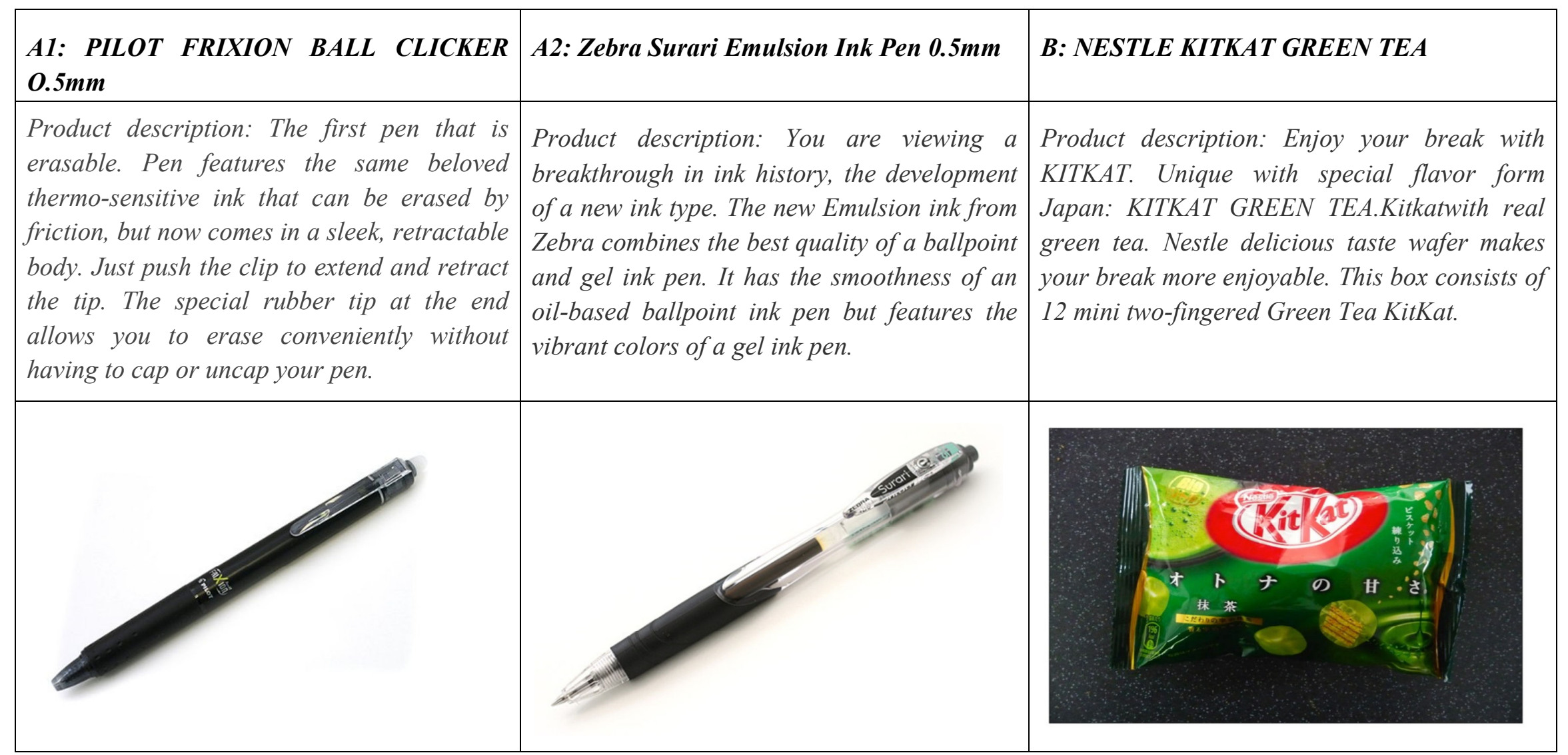


Hypothetical Choice (example of the questions).

Here we ask you to choose one of the following three products. Please cross the box under the product that you choose.

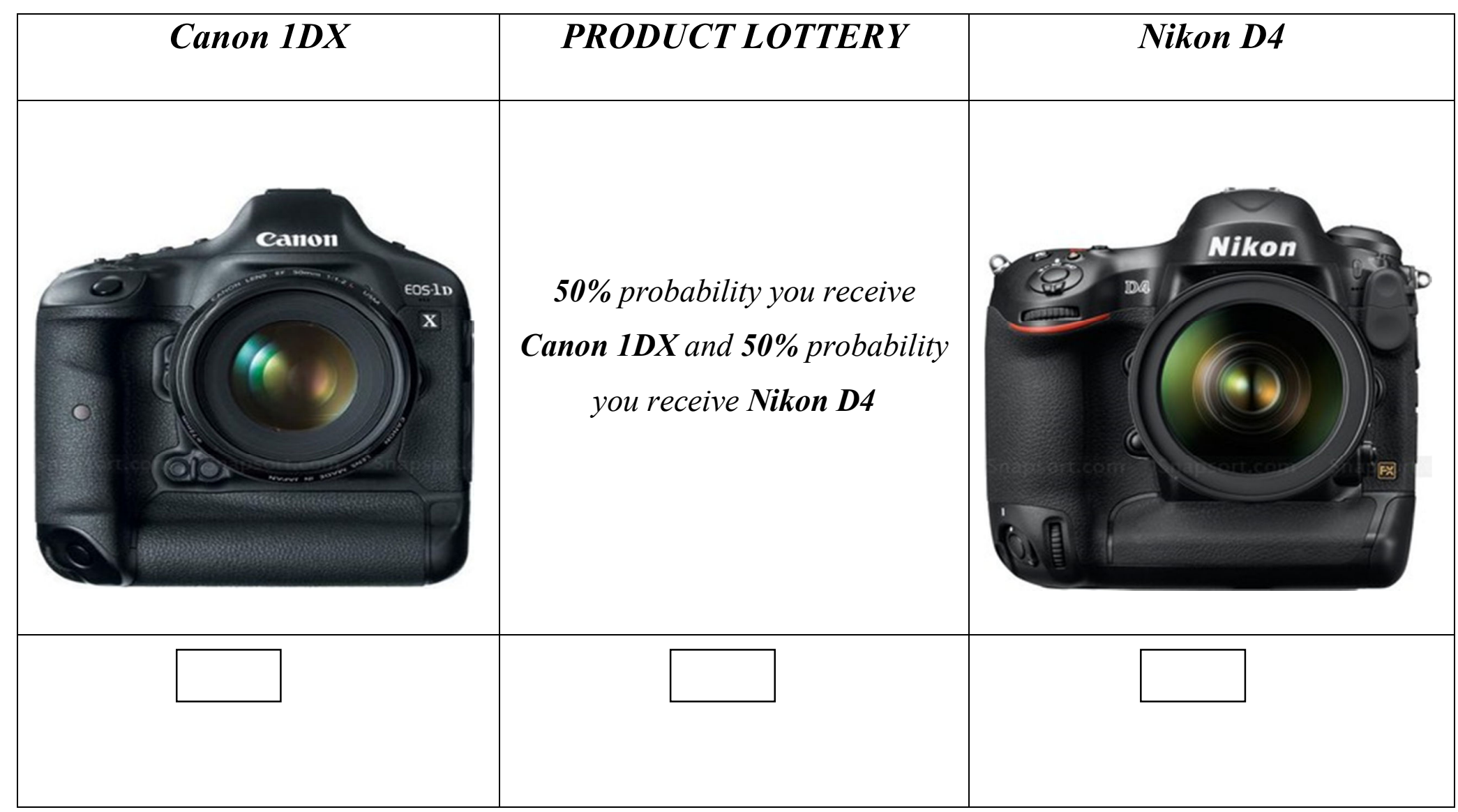

Reason for your choice: 